\title{
FERRAMENTAS DA QUALIDADE E SUAS APLICAÇÕES NA SOLUÇÃO DE
}

PROBLEMAS: estudo de caso em uma empresa do ramo automotivo

\section{QUALITY TOOLS AND THEIR APPLICATIONS IN TROUBESHOOTING: case study in}

\author{
an automotive company
}

Rafael Aparecido Ferreira Vitório - rafaelvitorio86@hotmail.com

Fabricio Domingues Antônio - fabricio.antonio@fatectq.edu.br

Faculdade de Tecnologia de Taquaritinga (Fatec) - Taquaritinga - São Paulo - Brasil

DOI: 10.31510/infa.v17i1.817

\section{RESUMO}

Durante os processos de produção de uma empresa, nos deparamos no dia a dia com problemas relacionados ao processo, aos equipamentos e colaboradores sem capacitação. Esses imprevistos impedem a programação de produção, ou até mesmo interferem na qualidade do produto final e, consequentemente, na credibilidade do seu cliente. Atender a satisfação do cliente é o que as empresas buscam, portanto, o sistema de gestão da qualidade tem que garantir que o produto final seja o resultado final do processo produtivo. Toda e qualquer não conformidade encontrada no processo será apresentado no produto final, mas para que isso não aconteça existem algumas ferramentas que podem ser utilizadas no processo. O presente artigo visa mostrar a importância dessas ferramentas em um processo de produção e como utilizá-las, de modo que traga benefícios à organização, eliminando desperdícios, tendo eficácia e ganho de produtividade e suporte na garantia do produto final. Através de um estudo de caso em uma empresa do ramo automotivo, foi apresentado a utilização de ferramentas da qualidade na solução do problema, trazendo um resultado positivo para não ocorrer mais a falha, servindo de modelo para outros itens de produção. Este trabalho foi desenvolvido com base em pesquisas bibliográficas por livros e artigos, e também através de um estudo de caso em uma empresa do ramo automotivo.

Palavras-chave: Gestão da qualidade. Ferramentas. Produto final.

\begin{abstract}
During the production processes of a company, we face problems related to the process, equipment and unskilled employees on a daily basis. These unforeseen events prevent the production schedule, or even interfere with the quality of the final product and, consequently, with the credibility of your customer. Meeting customer satisfaction is what companies seek, that's why the quality management system has to ensure that the final product is the result of the production process. Any and all non-conformities found in the process will be presented in the final product, but for that not to happen there are some tools that can be used in the process. This paper aims to show the importance of these tools in a production process and how to use them in a way that brings benefits to the organization, by eliminating wastes,
\end{abstract}


having efficiency and gains in productivity and support in guaranteeing the final product. Through a case study in an automotive company, it was presented the use of quality tools to solve the problem, bringing a positive result so that the failure does not occur anymore, serving as a model for other production items. This work was developed based on bibliographic searches through books and papers as well as a case study in an automotive company.

Keywords: Quality management. Tools. Final product.

\section{INTRODUÇÃO}

Está se tornando cada vez mais intensa nas empresas de hoje, a busca pela qualidade. Com a alta tecnologia atual e os recursos disponíveis, as empresas lutam por alcançar o nível máximo de qualidade de seus produtos e/ou serviços, mediante da alta concorrência de mercado.

Durante os processos de produção de uma empresa, nos deparamos no dia a dia com alguns problemas relacionados ao processo, matéria-prima ou até mesmo aos equipamentos. Estes imprevistos, acabam atrapalhando a programação de produção, ou até mesmo interferindo na qualidade do produto final.

Segundo Junior et al. (2010), atualmente qualidade é um termo que passou a ter muita importância nas organizações, independente do ramo de atividade da empresa. Qualidade hoje não está diretamente ligada apenas ao produto, mas também ao cliente e às suas necessidades de mercado. Não basta ter o melhor produto ou serviço, se o mesmo não estiver em acordo com o que o cliente procura para atender seu processo produtivo.

Nesse sentido, como aponta Palladini (2012, p. 4), "qualidade é a capacidade que um produto ou serviço tenha de sair conforme seu projeto". Ainda segundo Palladini (2012, p. 10), "qualidade é considerada como a falta de defeitos no produto ou no serviço prestado".

Diante do exposto, existem muitos aspectos simultâneos que envolvem a qualidade, uma diversidade de itens. A qualidade trata-se de um processo evolutivo, sofrendo alterações conceituais ao longo do tempo. A qualidade pode ser entendida como um conjunto de atributos ou elementos que compõem um produto ou serviço (PALLADINI, 2012).

\subsection{Objetivos e Justificativa}


O objetivo do presente artigo, é compreender a importância da qualidade dentro de uma organização, exibindo alguns meios e procedimentos para se evitar erros/falhas no processo que possam alterar a integridade do produto/serviço, bem como algumas ferramentas do qual o sistema de gestão da qualidade apresentam como suporte para identificar e auxiliar na análise e solução de problemas que interferem no bom desempenho do processo, permitindo melhorias nas tomadas de decisões.

\section{FUNDAMENTAÇÃO TEÓRICA}

\subsection{Conceito de qualidade}

Qualidade pode ser entendida como a satisfação do cliente em receber seu produto conforme estava previsto, satisfazendo sua necessidade ao uso destinado.

A qualidade enquanto conceito evoluiu ao longo do tempo de forma a adequar-se ao mercado, considerando a evolução dos negócios e a intensificação da concorrência, obrigando assim as organizações a gerarem uma constante busca pela melhoria contínua de seus produtos por meio do aprimoramento de seus processos. (LUPPI; ROCHA, 1998, apud DANIEL; MURBACK, 2014).

De acordo com Martins (2007, p.9, apud FREITAS et al., 2014) "É possível afirmar que em todas as visões de qualidade, indicam que o foco está direcionado principalmente à satisfação dos clientes e mercados e, consecutivamente, à melhora dos resultados empresariais".

\subsection{Gestão da qualidade no processo produtivo}

Segundo Fabris (2014), a gestão da qualidade vem se tornando uma estratégia competitiva, buscando conquistar mercados e também reduzir desperdícios. E para conquistar o mercado, é essencial que se atenda as exigências dos clientes.

"O raciocínio é muito simples: clientes satisfeitos representam faturamento, boa reputação, novos pedidos, resultados para a empresa, empregos e remuneração para os funcionários" (CARPINETTI; MIGUEL; GEROLAMO; 2009, p.1, apud FABRIS, 2014). 
De acordo com Paladini (2012), a Gestão da Qualidade sofreu impactos significativos no conceito de implantação da Qualidade Total. Anteriormente a qualidade só era avaliada concentrando-se apenas em resultados de atividades ou efeitos visando o produto acabado. Nos dias atuais, a ênfase está sendo a análise das causas direcionando todas as ações do processo produtivo para o atendimento ao cliente.

“Um roteiro prático para viabilizar a Gestão da Qualidade no processo envolve a implantação de atividades agrupadas em três etapas: a eliminação de perdas, a eliminação das causas das perdas e a otimização do processo" (PALADINI, 1995, apud PALADINI, 2012, p.21). Os Quadros 1, 2 e 3 a seguir, abordam as três etapas de forma detalhada.

Quadro 1 - Etapa 1

\begin{tabular}{|c|c|}
\hline \multicolumn{2}{|r|}{ Eliminação de perdas } \\
\hline $\begin{array}{c}\text { Atividades } \\
\text { Características }\end{array}$ & $\begin{array}{l}\text { Eliminação de defeitos, refugos e retrabalho. } \\
\text { Emprego de programas de redução dos erros da mão de obra. } \\
\text { Esforços para minimizar custos de produção. } \\
\text { Eliminação de esforços inúteis (como reuniões inconclusivas). }\end{array}$ \\
\hline $\begin{array}{l}\text { Naturezas } \\
\text { das Ações }\end{array}$ & $\begin{array}{l}\text { Corretivas (visam eliminar falhas do sistema). } \\
\text { Ações direcionadas para elementos específicos do processo. } \\
\text { Alvo: limitado, bem definido. } \\
\text { Resultados: imediatos. }\end{array}$ \\
\hline Prioridade & Minimizar desvios da produção. \\
\hline Observações & $\begin{array}{l}\text { Não se acrescenta nada ao processo. } \\
\text { Eliminam-se desperdícios. }\end{array}$ \\
\hline
\end{tabular}

Fonte: Paladini (2012)

Quadro 2 - Etapa 2

\begin{tabular}{|c|l|}
\hline \multicolumn{2}{|c|}{ Eliminação das causas de perdas } \\
\hline \multirow{3}{*}{ Atividades } & Estudo das causas de ocorrência de defeitos ou de situações que \\
Características & Controle estatístico de defeitos (exemplo: frequência de detecção \\
& relacionada a ambiente ou a condições de ocorrência). \\
& Desenvolvimento de projetos de experimentos voltados para a relação \\
\hline
\end{tabular}




\begin{tabular}{|c|c|}
\hline & $\begin{array}{l}\text { entre causas e efeitos. } \\
\text { Estruturação de sistema de informações para monitorar a produção e } \\
\text { avaliar reflexos, no processo, de ações desenvolvidas (como eliminar } \\
\text { estoques para compensar perdas de peças). }\end{array}$ \\
\hline $\begin{array}{l}\text { Natureza } \\
\text { das Ações }\end{array}$ & $\begin{array}{l}\text { Preventivas. } \\
\text { Ênfase: eliminar causas de falhas do sistema. } \\
\text { Meta: corrigir o mau uso dos recursos da empresa. } \\
\text { Ações direcionadas para áreas ou etapas do processo de produção, } \\
\text { setores da fábrica ou grupos de pessoas. } \\
\text { Alvo: obter níveis de desempenho do processo produtivo em função de } \\
\text { ações que foram desenvolvidas. } \\
\text { Resultados: médio prazo. }\end{array}$ \\
\hline Prioridade & $\begin{array}{l}\text { Evitar situações que possam conduzir a desvios da produção, } \\
\text { eliminando-se elementos que a prejudiquem e gerando-se condições } \\
\text { mais adequadas para seu funcionamento normal. }\end{array}$ \\
\hline Observações & $\begin{array}{l}\text { Aqui, considera-se perda toda e qualquer ação que não agrega valor ao } \\
\text { produto (perda }=\text { qualquer ação que não aumente a adequação do } \\
\text { produto a seu uso efetivo). } \\
\text { Esta etapa requer atividades de difícil implantação e de avaliação mais } \\
\text { complexa, mas aqui pode-se visualizar se estão ocorrendo melhorias em } \\
\text { termos da qualidade. }\end{array}$ \\
\hline
\end{tabular}

Fonte: Paladini (2012) 
Quadro 3 - Etapa 3

\begin{tabular}{|c|c|}
\hline \multicolumn{2}{|r|}{ Otimização do processo } \\
\hline $\begin{array}{c}\text { Atividades } \\
\text { Características }\end{array}$ & $\begin{array}{l}\text { Novo conceito da qualidade, eliminando a ideia de que qualidade é a } \\
\text { falta de defeitos mas, sim, a adequação ao uso. } \\
\text { Aumento da produtividade e da capacidade operacional da empresa. } \\
\text { Melhor alocação dos recursos humanos da empresa. } \\
\text { Otimização dos recursos da empresa (como materiais, equipamentos, } \\
\text { tempo, energia, espaço, métodos de trabalho ou influência ambiental). } \\
\text { Adequação crescente entre produto e processo; processo e projeto e } \\
\text { projeto e mercado. } \\
\text { Estruturação de sistemas de informações para a qualidade. }\end{array}$ \\
\hline $\begin{array}{l}\text { Natureza } \\
\text { das Ações }\end{array}$ & $\begin{array}{l}\text { Atividades destinadas a gerar resultados benéficos à organização de } \\
\text { forma permanente. } \\
\text { Resultados de longo prazo. } \\
\text { Ações abrangentes, dirigindo-se para todo o processo (alvo a atingir) } \\
\text { Atuação tanto em termos de resultados individuais de áreas, grupos de } \\
\text { pessoas ou setores, como na interface entre eles, enfatizando } \\
\text { contribuições (individuais ou coletivas) para o resultado global do } \\
\text { processo. }\end{array}$ \\
\hline Prioridade & $\begin{array}{l}\text { Definir potencialidades da produção, enfatizando o que o processo tem } \\
\text { de melhor hoje e o que é capaz de melhorá-lo ainda mais. }\end{array}$ \\
\hline Obervações & $\begin{array}{l}\text { Esta é a única etapa que agrega, efetivamente, valor ao processo e, } \\
\text { consequentemente, ao produto. }\end{array}$ \\
\hline
\end{tabular}

Fonte: Paladini (2012)

É notável nesta última etapa, conforme pode ser observado no Quadro 3, o conceito de melhoria contínua, direcionando o processo aos objetivos da organização, harmonizando metas operacionais, táticas e estratégicas para o gerenciamento da empresa.

Ao analisar as três etapas, pode-se verificar a evolução gradual das atividades acerca dos processos, contribuindo assim, para a adequação do produto ao seu uso. 
“A maioria das estratégias de Gestão da Qualidade utiliza avaliações, as quais ficam evidentes quando utilizados técnicas de avaliação de processos produtivos e, em particular o Controle Estatístico de Processo (CEP)" (PALADINI 2012, apud FREITAS et al., 2014).

\subsection{Controle Estatístico de Processo (CEP)}

Conforme Montgomery (2004, apud MAICZUCK; JUNIOR, 2013), o Controle Estatístico de Processo (CEP) é uma ferramenta muito utilizada na melhoria de processos. Com ela é possível prever defeitos, aumentar a produtividade e realizar ajustes no processo.

De acordo com Maiczuk e Junior (2013), o CEP é uma metodologia que atua de forma preventiva em um processo produtivo, fazendo com que o mesmo ocorra em condições ideais e controladas, a fim de manter os parâmetros preestabelecidos e reduzir a variação das características críticas dos produtos, obtendo assim mais segurança na garantia da qualidade e menor custo.

\subsection{Trilogia de Juran}

De acordo com Juran (2011), o gerenciamento para a qualidade é feito através de 3 processos: Planejamento da qualidade, Controle da qualidade e Melhoramento da qualidade.

- Planejamento da qualidade: é o desenvolvimento dos produtos e processos necessários para satisfazer as necessidades dos clientes. Para isso requer alguns passos: estabelecer quais as metas de qualidade, identificar quem são os clientes, quais são suas necessidades em relação ás características dos produtos, estabelecer quais os controles de processo e transladar os planos de resultados para as forças operacionais.

- Controle da qualidade: este processo e decorrente dos seguintes passos: avaliar o desempenho da qualidade real, comparando-o com as metas estabelecidas de qualidade e se necessário, atuar nas diferenças.

- Melhoramento da qualidade: este processo busca maneiras para elevar o desempenho da qualidade a níveis inéditos. Para isso segue os seguintes passos: estabelecer a infraestrutura necessária, os recursos necessários para os projetos de melhorias, 
estabelecer uma equipe designada para cada projeto tendo em vista a responsabilidade de alcançar um resultado de sucesso e prover treinamentos e a motivação das equipes.

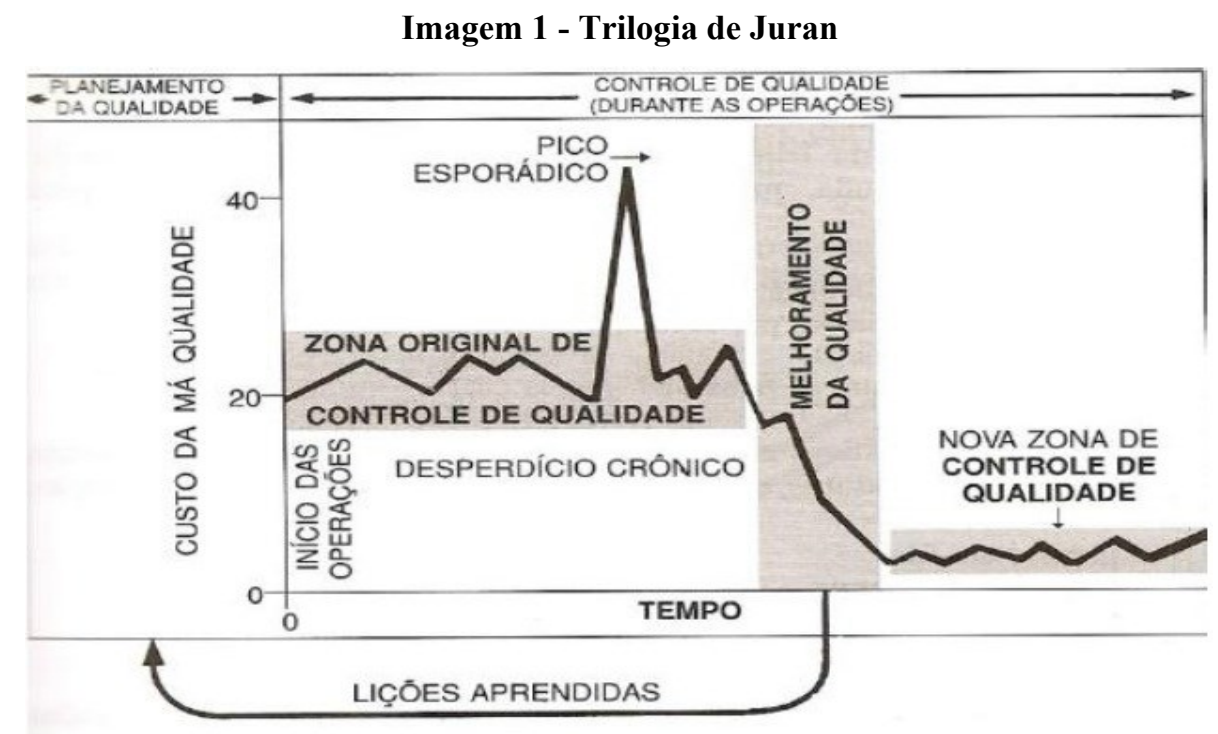

Fonte: Juran (2011)

\section{PROCEDIMENTOS METODOLÓGICOS}

A empresa em estudo é do seguimento automotivo, está localizada na cidade de Monte Alto/SP, contendo em torno de 160 colaboradores. Seu principal produto é o Volante Motor, que é utilizado em carros de câmbio manual. Por se tratar de uma empresa que está a mais de um século no mercado automotivo, torna-se imprescindível manter a alta qualidade de seus produtos atendendo as necessidades dos clientes para se manter ativa num mercado tão competitivo como atualmente.

Este trabalho foi desenvolvido por meio de um estudo de caso na empresa citada, seguida de pesquisa exploratória fazendo uma análise e observação do problema encontrado, podendo assim ter informações para prosseguir com os procedimentos de solução.

Durante o processo de produção, o item volante-motor é fabricado em uma linha robotizada. Cada peça produzida passa por uma sequência de produção, e uma delas é a gravação Data-Matrix, que identifica a rastreabilidade da peça. Em um determinado lote de produção, foi identificada uma falha no processo de gravação Data-Matrix, onde foram encontradas 5 peças com a gravação fora de posição do que determina o cliente. Este 
problema impacta na linha de montagem da montadora, pois o leitor Data-Matrix que fica fixo, não consegue realizar a leitura sendo que a mesma está fora de posição.

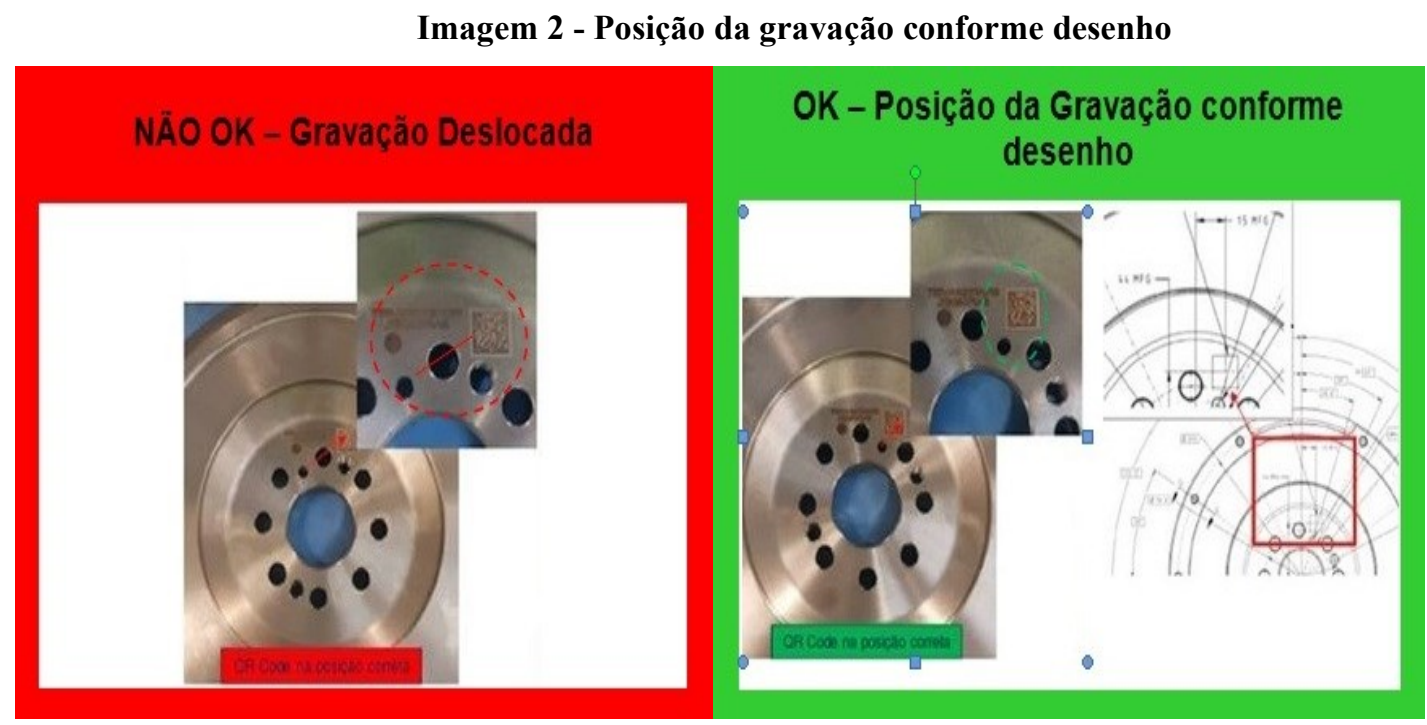

Fonte: o autor (2020)

A seguir serão apresentadas as ferramentas da qualidade utilizadas para solucionar este problema e também as medidas tomadas para não ocorrer novamente esta falha.

\subsection{Fluxograma de produção da peça}

De acordo com Junior et al. (2010), fluxograma é uma forma de representação gráfica, permitindo a visualização de um processo seguindo passo a passo. Apresenta uma visão incorporada do fluxo de um processo seja ele técnico, administrativo ou gerencial, permitindo uma análise crítica detectando falhas e melhorias.

A seguir, está demonstrado em forma de um fluxograma, o processo e o fluxo da peça desde a entrada da peça bruta até a saída do produto semiacabado na linha de produção. 
Quadro 4 - Fluxograma do processo
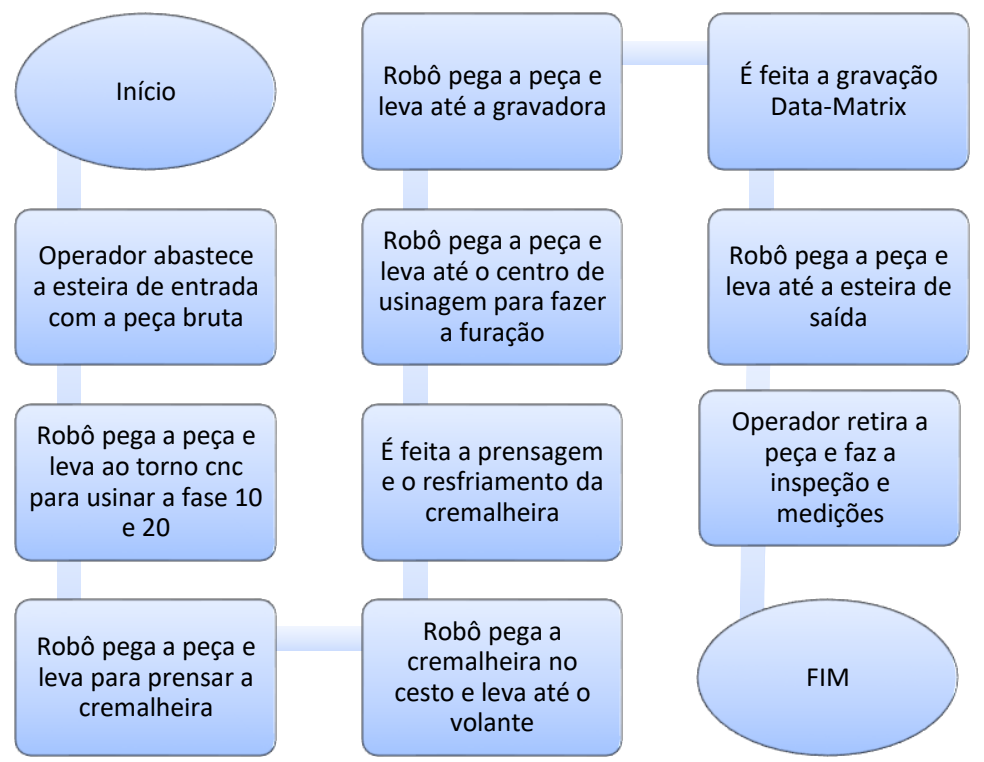

Operador retira a

peça e faz a

inspeção e

medições

Fonte: o autor (2020)

\subsection{Diagrama de Causa e Efeito}

De acordo com Junior et al. (2010), o diagrama de Ishikawa ou Diagrama de Causa e Efeito, é uma ferramenta da qualidade que ajuda a levantar as possíveis causas de um determinado efeito, analisando todos os fatores que envolvem a execução do processo.

Quadro 5 - Diagrama de causa e efeito

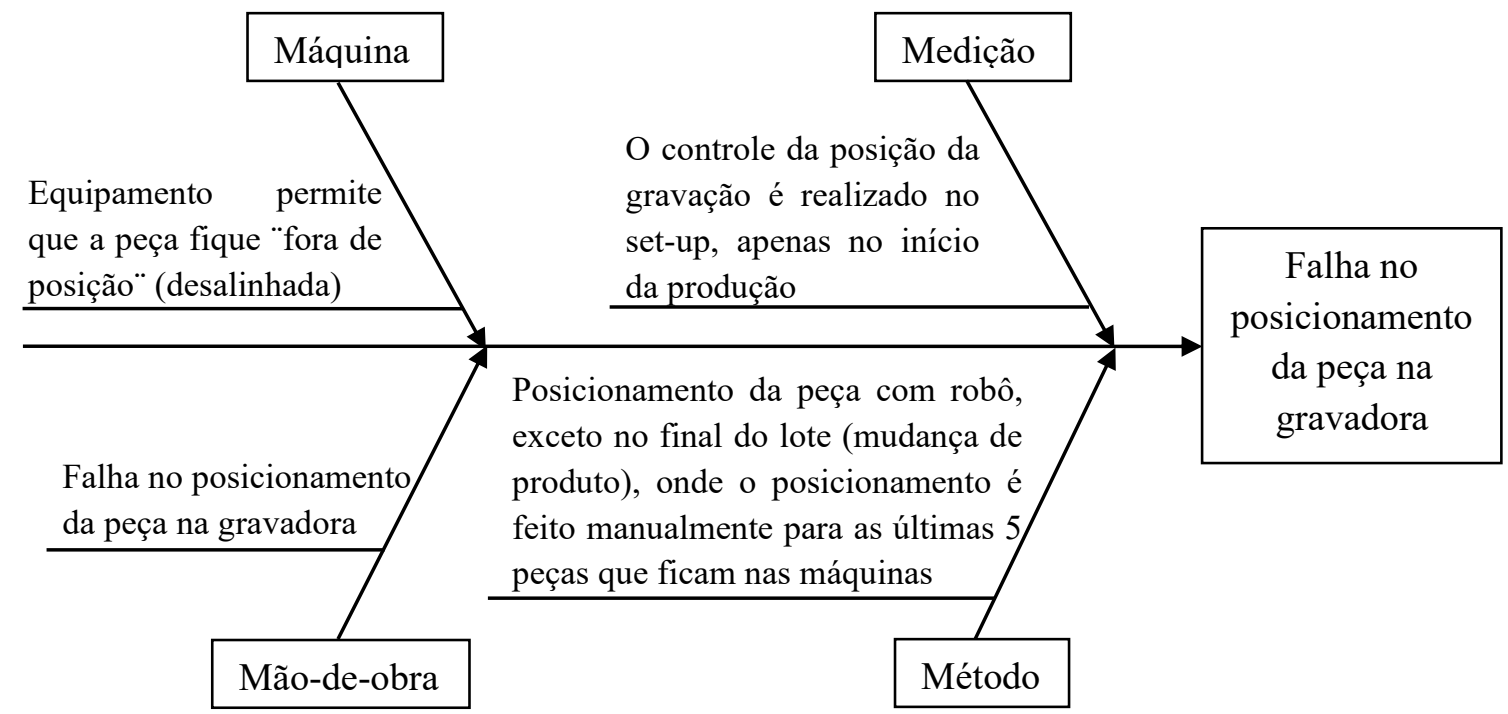

Fonte: o autor (2020) 


\section{$3.35 \mathrm{~W} 2 \mathrm{H}$}

Conforme Junior et al. (2010) a planilha 5W2H é uma ferramenta utilizada para mapear e padronizar processos, elaborar planos de ação, definir responsabilidades, métodos, prazos e objetivos. Define também quem, quando, onde, por que, como e quanto isto irá custar para a empresa.

Quadro 6 - Planilha 5W2H das ações que foram tomadas

\begin{tabular}{|c|c|c|c|c|c|c|}
\hline \multicolumn{7}{|c|}{ Planilha 5W2H } \\
\hline O que? & Quem? & Onde? & Por quê? & Quando? & Como? & Quanto? \\
\hline $\begin{array}{l}\text { Fabricar um } \\
\text { dispositivo de } \\
\text { posicionamen } \\
\text { to da peça }\end{array}$ & Ferramentaria & $\begin{array}{c}\mathrm{Na} \\
\text { empresa }\end{array}$ & $\begin{array}{l}\text { Para posicionar a } \\
\text { peça corretamente } \\
\text { quando for feita } \\
\text { gravação manual }\end{array}$ & abril/20 & $\begin{array}{l}\text { O processo irá } \\
\text { desenvolver o } \\
\text { dispositivo } \\
\text { adequado }\end{array}$ & $\mathrm{R} \$ 100,00$ \\
\hline $\begin{array}{l}\text { Fabricar um } \\
\text { dispositivo de } \\
\text { controle (tipo } \\
\text { máscara) }\end{array}$ & Ferramentaria & $\begin{array}{c}\mathrm{Na} \\
\text { empresa }\end{array}$ & $\begin{array}{c}\text { Para fazer a } \\
\text { verificação da } \\
\text { gravação no próprio } \\
\text { posto de trabalho }\end{array}$ & abril/20 & $\begin{array}{l}\text { O processo e a } \\
\text { Qualidade irão } \\
\text { desenvolver o } \\
\text { dispositivo } \\
\text { adequado }\end{array}$ & $\mathrm{R} \$ 200,00$ \\
\hline $\begin{array}{c}\text { Enxaixar a } \\
\text { peça no } \\
\text { dispositivo de } \\
\text { fixação }\end{array}$ & Operador & $\begin{array}{c}\mathrm{Na} \\
\text { gravadora }\end{array}$ & $\begin{array}{c}\text { Para que não ocorra } \\
\text { mais erro na } \\
\text { gravação }\end{array}$ & - & $\begin{array}{l}\text { Encaixar a peça } \\
\text { nos pontos de } \\
\text { fixação do } \\
\text { dispositivo }\end{array}$ & - \\
\hline $\begin{array}{c}\text { Inspecionar as } \\
\text { peças } \\
\text { gravadas } \\
\text { manualmente }\end{array}$ & Operador & $\begin{array}{c}\mathrm{Na} \\
\text { gravadora }\end{array}$ & $\begin{array}{c}\text { Para que não ocorra } \\
\text { mais erro na } \\
\text { gravação }\end{array}$ & - & $\begin{array}{l}\text { Fazer inspeção } \\
\text { visual de } \\
\text { acordo com o } \\
\text { desenho da } \\
\text { peça }\end{array}$ & - \\
\hline
\end{tabular}

Fonte: o autor (2020)

\section{RESULTADOS E DISCUSSÃO}

Após o levantamento do problema, foram analisadas as possíveis causas que poderiam ocasionar o defeito na peça. Nesse sentido, foram realizados testes que apontaram que o defeito estava relacionado à falha humana, além da falha no processo que não havia sido considerada, isto é, deficiência no posicionamento manual da peça para efetuar a gravação.

Diante da identificação das falhas, foi desenvolvido um dispositivo de fixação da peça contribuindo assim para que não ocorra falhas de posicionamento, além do dispositivo, 
também foi desenvolvida uma máscara de controle para que o operador possa conferir a posição da gravação nas peças que forem gravadas manualmente ao fim do lote de produção.

Ademais, foram inseridas nas fichas de controle as mudanças efetuadas no processo como forma de padronização das atividades, possibilitando assim, que todos os operadores da linha de produção analisada sigam os procedimentos corretamente. Além disso, foram oferecidos treinamentos aos funcionários com o objetivo de assimilarem no seu dia a dia a utilização dos dispositivos inseridos no processo.

Com as correções, não houve diminuição no tempo de produção pelo fato de que as últimas peças são gravadas manualmente, porém, houve redução total dos retrabalhos, pois devido à instalação do dispositivo de fixação não ocorreu mais nenhuma falha de gravação.

\section{CONSIDERAÇÕES FINAIS}

Este artigo foi desenvolvido a partir de uma revisão bibliográfica e da aplicação de princípios em um estudo de caso. Foram destacados fatores de grande importância na gestão da qualidade, assim como, quanto à utilização de ferramentas de qualidade que podem contribuir positivamente no processo das empresas. O conteúdo transparece técnicas e procedimentos a serem seguidos para melhorar o processo com a finalidade de diminuir perdas/desperdícios, antecipando o surgimento de problemas.

No passado a qualidade buscava apenas a qualidade do produto final, o que hoje não é suficiente para empresas que buscam o aperfeiçoamento da qualidade para se manter na frente de suas concorrentes levando em consideração o cenário atual em que as empresas se encontram em meio ao mercado competitivo. Hoje a preocupação da qualidade é direcionada ao processo de forma geral, buscando atender todos os requisitos e necessidades do cliente.

As ferramentas apresentadas neste trabalho, assim como outras existentes que não foram abordadas aqui, auxiliam no gerenciamento dos processos buscando sempre obter melhorias, com o objetivo de garantir que a qualidade dos produtos/serviços possa atingir o nível esperado não só pela organização, mas principalmente do cliente. 


\section{REFERÊNCIAS}

DANIEL, Érika A.; MURBACK, Fábio G. R. Levantamento bibliográfico do uso das ferramentas da qualidade. Poços de Calda, 2014. Disponível em <

https://www.pucpcaldas.br/graduacao/administracao/revista/artigos/v2014/Artigo16_2014.pdf >. Acesso em: 09 abr. 2020.

FABRIS, Caroline B. Aplicação das ferramentas da qualidade em um processo produtivo em uma indústria de ração. Medianeira, 2014. Disponível em:

$<$ http://repositorio.roca.utfpr.edu.br/jspui/bitstream/1/4327/1/MD_COENP_TCC_2014_2_03. pdf $>$. Acesso em: 08 abr. 2020.

FREITAS, Kaliany et al. Aplicação das ferramentas da qualidade em uma panificadora como método de melhoria do processo produtivo: estudo de caso. Curitiba, 2014.

Disponível em: <

http://www.abepro.org.br/biblioteca/enegep2014_TN_STO_196_109_26161.pdf>. Acesso em: 08 abr. 2020.

JUNIOR, Isnard M. et al. Gestão da Qualidade. 10. ed. Rio de Janeiro: Editora FGV, 2010.

JURAN, J.M. A Qualidade desde o projeto: novos passos para o planejamento da qualidade em produtos e serviços J. M. Juran; tradução de Nivaldo Montingelli Jr. - São Paulo: Cengage Learning, 2011.

MAICZUK, J.; JUNIOR, P. P. A. Aplicação de ferramentas de melhoria de qualidade e produtividade nos processos produtivos: um estudo de caso. Qualit@s Revista Eletrônica ISSN 16774280 Vol.14. No 1(2013). Disponível em:

<http://revista.uepb.edu.br/index.php/qualitas/article/viewFile/1599/924>. Acesso em: 09 abr. 2020 .

PALADINI, Edson P. Gestão da Qualidade: teoria e prática / Edson Pacheco Paladini. 3. ed. São Paulo: Atlas, 2012. 